\title{
Study of the Effect of Sulphide Stress Corrosion on the Load Bearing Capability of API 5L Grade B Steel used in Petroleum Pipelines
}

\author{
M.D.H.C. Peiris, L.W.L. Perera and G.I.P. De Silva
}

\begin{abstract}
The Phenomenon of Sulfide Stress Corrosion (SSC) can result in catastrophic failures in pressurized equipment and piping leading to extensive damages, injuries and possible fatalities. SSC, a major degradation process in metals, is commonly associated with the petroleum industry where a high concentration of $\mathrm{H}_{2} \mathrm{~S}$ is involved. For pipelines in the petroleum and natural gas industries, API 5L Grade B Steel type is extensively used. This research focuses on developing a correlation between load at fracture and time period exposed to a constant $\mathrm{H}_{2} \mathrm{~S}$ concentration under a constant load. Furthermore, the mechanism of growing the depth of corrosion is studied in terms of microstructural analysis. Correlations of depth of corrosion versus exposure time and load at fracture versus exposure time have been developed. It was concluded that variation of the load at fracture with the depth of corrosion closely fits the proposed model within the $55 \mu \mathrm{m}$ to $80 \mu \mathrm{m}$ depth range. Additionally, the progress of developing micro cracks towards the unaffected metal has significantly contributed to the drastic reduction in load bearing capability beyond the depth of corrosion around $55 \mu \mathrm{m}$. The results showed that the combined effect of developing of microcracks and formation of sulfides within the corrosion layer and base metal has led to the ultimate brittle fracture of specimens.
\end{abstract}

Keywords: Sulphide Stress Corrosion, API 5L Steel, Depth of Corrosion, $\mathrm{H}_{2} \mathrm{~S}$ Concentration, Load at Fracture

\section{Introduction}

The term "Sulfide Stress Corrosion (SSC)" is a customary term for aqueous corrosion in the presence of hydrogen sulfide $\left(\mathrm{H}_{2} \mathrm{~S}\right)$ at a level high enough to significantly affect the corrosion behavior and corrosion products compared with the same condition without $\mathrm{H}_{2} \mathrm{~S}$ [1]. The rate of corrosion is predominantly influenced by $\mathrm{H}_{2} \mathrm{~S}$ concentration, applied load/pressure and exposure time period. Sulfide stress corrosion is an unavoidable issue associated with the petroleum industry, due to persistent presence of $\mathrm{H}_{2} \mathrm{~S}$ which naturally occurs during drilling and refinement of crude oil. The pipelines used in petroleum industry are made of carbon steel. API 5L Grade B steel is extensively used for crude oil pipeline construction due to its high strength and ductility value [2].

Currently, Sri Lanka has one petroleum refinery and it is facing significant effects of corrosion due to $\mathrm{H}_{2} \mathrm{~S}$ at desulphurization unit in the process plant. During the recent past, Sri Lanka has found commercial quantities of gas in the northern offshore areas of the country and new challenges can be expected with the presence of higher levels of $\mathrm{H}_{2} \mathrm{~S}$ in the gas expected to be extracted. SSC is a combination of forming sulfide layers at the surface of metals and developing minor cracks at the subsurface when exposed to wet hydrogen sulfide environments [3]. Surface recombination of the diffused atomic hydrogen is inhibited by the presence of adsorbed sulfur and results in enhanced hydrogen permeation to the metal, preferentially along grain boundaries. Formation of molecular hydrogen occurs within inherently occurring voids such as grain boundary triple junctions, laminations and non-metallic inclusions, and building a pressure at these voids, resulting in crack formation [4].

In general, SSC is found to be confined to highly stressed regions where Hydrogen accumulates preferentially, and susceptible microstructure determines the critical level of hydrogen content required for crack initiation and growth. SSC susceptibility of steel has been observed to be at its maximum at room temperature [5].

\footnotetext{
Eng. M.D.H.C. Peiris, B.Sc. Eng. (Hons) (Moratuwa),

Email:peiris.mdhc@gmail.com

(ib http://orcid.org/0000-0002-8706-452X

Mr. L.W.L. Perera, B.Sc. Eng. (Hons) (Moratuwa),

Email:lpererarox@gmail.com

(iD http://orcid.org/0000-0003-1581-8393 Eng. (Dr.)

G.I.P. De Silva, CEng., MIE(SL), B.Sc. Eng. (Hons)

(Moratuwa) M.Phil. (Moratuwa), Ph.D. (Kochi, Japan),

Senior lecturer, Department of Materials Science and

Engineering, University of Moratuwa.

Email:indikagip@uom.lk

(iD http://orcid.org/0000-0002-8792-3494
} 
Generally, the SSC susceptibility of high strength steels [6] has been estimated using various qualitative tests [7] which include the NACE TM-0177 tension test. Furthermore, NACE has issued a series of guidelines for safe operation in $\mathrm{H}_{2} \mathrm{~S}$ environments (NACE MR0175-93). Accordingly, the strength of sulfide stress corrosion resistant steels has been limited to steels with maximum yield strength of 690 $\mathrm{MPa}$ and hardness of 22 HRC. Thus, in applications requiring higher load handling capabilities, this form of degradation presents a major challenge where equipment life cycle, maintenance and safety are concerned.

Despite the considerable amount of research effort that has been expended on the investigation of sulfide stress corrosion mechanism, to date there is a lack of consensus on how degradation process occurs with formation of sulfides and recombination of hydrogen at the subsurface. It is generally agreed that the combination of the precipitation of molecular hydrogen in micro voids [8] and the decohesion theory [9] are mostly valid and may be used to explain most observations found in SSC failures [10]. To predict and understand the impact of $\mathrm{H}_{2} \mathrm{~S}$ on corrosion, it is deemed important to anticipate the type of iron sulfides formed at given conditions. The formed corrosion layer during the SSC consists primarily of multilayers of $\mathrm{FeS}$. Figure 1 illustrates an example of such a layered structure [11]. It includes three corroded layers with different chemical compositions separated by distinct boundaries. Generally, sulfides can form layered structures because of the large polarizability of the anions. In Figure 1, the innermost corroded layer standing next to the steel surface comprises mostly iron and oxygen. In addition it can contain some amount of sulfur, with traces of magnetite, iron carbonate and iron sulfide [3]. On top of the iron oxide layer there is a layer of sulphur deficient $\mathrm{FeS}$ followed by a layer of sulfur rich FeS.

Several researchers [12]-[14] discussed that currently, there is no generally accepted model to predict the rate of SSC. Therefore, this study would be highly beneficial for the petroleum industry in terms of prediction of the rate of SSC in pipelines as this phenomenon can result in catastrophic failures of pressurized equipment and piping. Furthermore, it supports the optimization of service schedule, reduction of maintenance cost and increasing the degree of safety within the industrial environment.

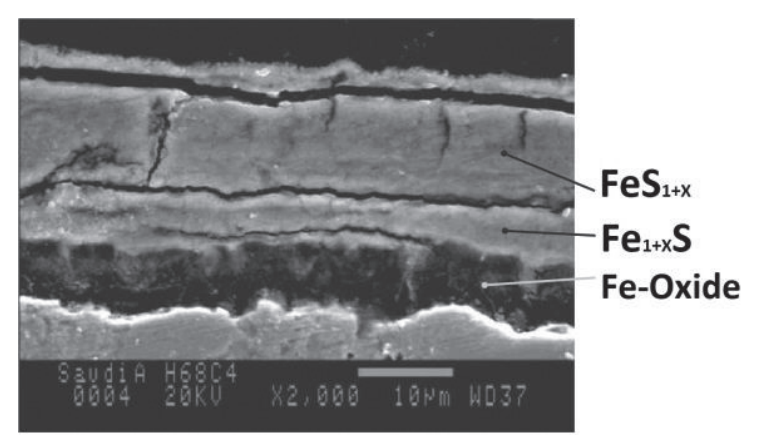

Figure 1 - Formation of Multilayers of Iron Sulfides in Sulfide Stress Corrosion [11]

\section{Methodology}

\subsection{Selection of Pipeline Steel Samples}

This research focuses on developing a correlation between load at fracture and time period exposed to a constant $\mathrm{H}_{2} \mathrm{~S}$ concentration under a constant applied load. The material to be tested, API 5L Grade B Steel, was procured from the Ceylon Petroleum Corporation in the form of a seamless pipe of $1 \mathrm{~m}$ in length with a thickness of $11 \mathrm{~mm}$, and a diameter of $168 \mathrm{~mm}$ which satisfied ANSI/NACE TM0177 specimen requirements as well as the testing apparatus parameters [15]. The specimen was subjected to Atomic Emission Spectroscopy to verify the alloy composition. The constant load test method was carried out in accordance with the ANSI/NACE TM0177 sour service testing standard [5].

\subsection{Sample Preparation}

Seventy-two tensile specimens were machined in accordance with dimensions given in the ANSI/NACE TM-0177 standard. The specimens were machined in the longitudinal direction of the pipe.

\section{Preliminary Microstructural Observation and Rating of Inclusions}

Microstructural observations were carried out for two samples from the testing material using an optical microscope to assure the microstructural features in the original samples. Another two samples were observed microscopically without etching and the inclusion rating was rated as per ASTM E45 (2005) [17].

\section{Determining the Value of Applied Load}

Maximum allowable working pressure was (back-calculated and averaged from the typical pressures in the overhead piping of platformate unit in the CPC refinery (equivalent to $234 \mathrm{psi}$ ), using the following equation (ASME B 31.3 3a(1996)) [18]. 


$$
t=\frac{P D}{2(S E+P Y)} \approx \frac{P D}{2 S E}
$$

Where $P=$ Design gauge internal pressure (240psi), $D=$ Outside Diameter $(168.3 \mathrm{~mm}$ /6.625 in), $t=$ pipeline thickness $(10.97 \mathrm{~mm}$ /0.432 in), $S=$ Hoop Stress, $E=$ Quality Factor which is 1 (up to $482 \mathrm{deg}$ C.), $Y=$ coefficient from Table 304.1.1 valid for $t<D / 6$ and for ferritic materials (0.4). The stress is then translated to the load through four samples (Figure 2) by $P=F / A$ where $P=$ axial stress through sample, $F=$ load applied on sample and $A=$ cross sectional area $\left(19.64 \mathrm{~mm}^{2}\right)$ of the gauge of standard sample [5] assuming axial stress is one half of the hoop stress.

\section{Preliminary Investigations to Distinguish the} Effects of Load and $\mathrm{H}_{2} \mathrm{~S}$ Environment

Sample sets comprising four samples were kept in the corrosion chamber in a neutral aqueous environment for a period of two weeks. One set of samples was kept under the load of $500 \mathrm{~N}$, while another set was kept without being loaded (Figures 2 and 3). Subsequently, samples were kept in the corrosion chamber with the same load applied previously for two weeks in two separate experiments. One set of samples was kept at constant $\mathrm{H}_{2} \mathrm{~S}$ concentration- $\mathrm{pH}$ value of $3.0 \pm 0.5$, while another set was kept at neutral aqueous environment. After exposure to their respective environments for a fixed period of two weeks, the samples were taken out and tensile tests were performed to test the load at fracture, and the microstructures of cross sections perpendicular to the load applying direction were observed using a high magnification optical microscope to estimate the average depth of corrosion.

\section{Varying the Exposure Time under Constant Load and $\mathrm{H}_{2} \mathrm{~S}$ Concentration}

Six sets of samples, comprising four samples in each set (Three for tensile testing, one for axial cross sectional microstructural observation) were kept in the corrosion chamber, held under a constant load of $500 \mathrm{~N}$ and $\mathrm{H}_{2} \mathrm{~S}$ concentration$\mathrm{pH}$ value of $3.0 \pm 0.5$ for time periods from 2 to 14 weeks in two week incremental periods in separate sessions. Thereafter the corroded samples (Figure 4) were taken out from the chamber and three of them were subjected to tensile tests to test the load at fracture.
Corrosion Behaviour in terms of Microstructural Analysis

The remaining sample taken from each set was used to observe microstructure of cross section perpendicular to the direction which the load is applied to estimate the average depth of corrosion. Furthermore, other selected areas including corroded layer and the subsurface from the same cross section were subjected to microstructural investigations and elemental mapping using SEM/EDS.

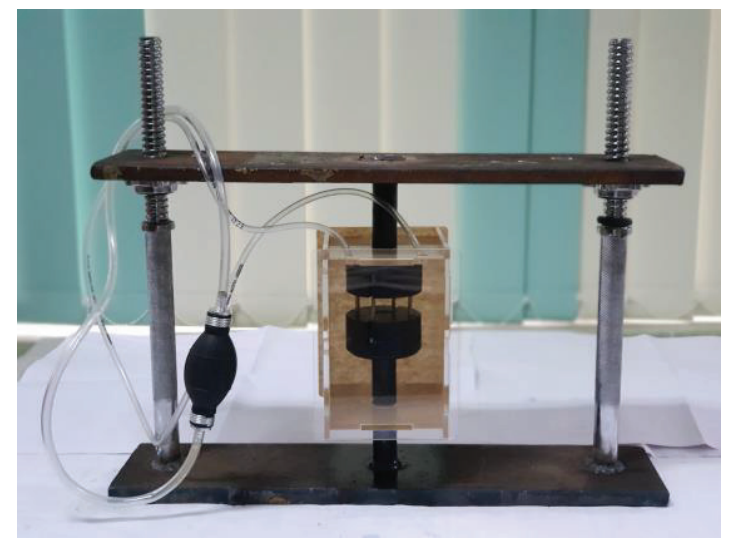

Figure 2 - Corrosion Chamber with Specimens under Loaded Condition

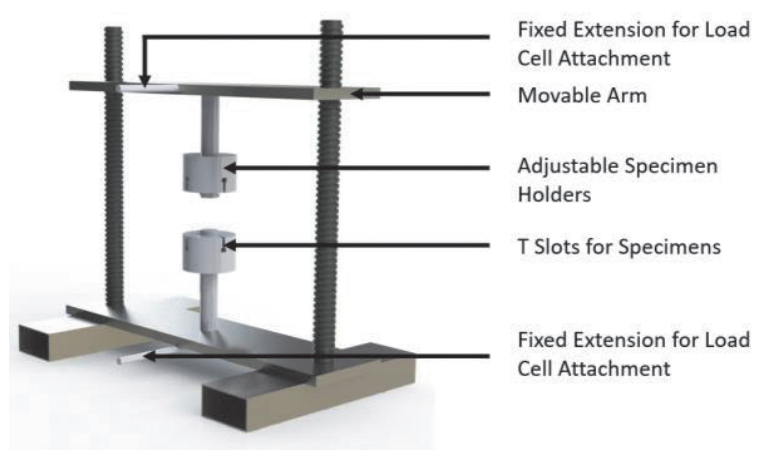

Figure 3 - Set up for Applying the Constant Load $(500 \mathrm{~N})$ to the Specimen

\section{Results and Discussion}

Steel samples obtained from Ceylon Petroleum Corporation were assured as API 5L Grade B Steel based on the results of chemical analysis shown in Table 1. 

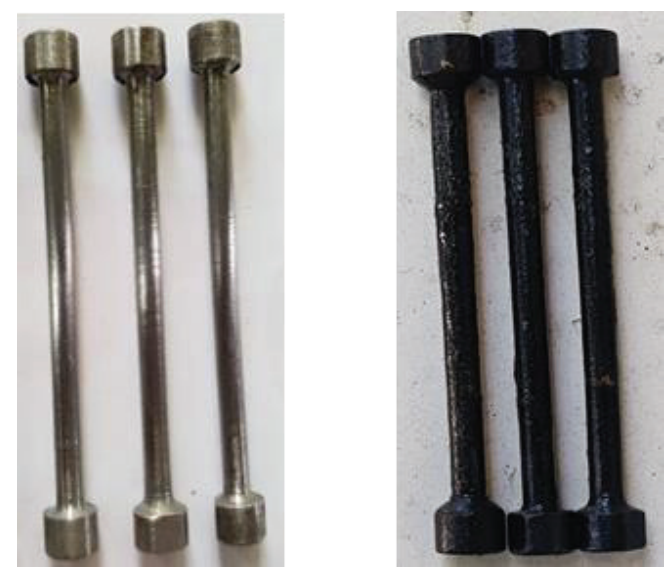

Figure 4 - Original Specimen Vs. Corroded Specimen (Week 06)

Table 1 - Elemental Composition of the Specimens Tested

\begin{tabular}{ccc}
\hline Element & Weight \% & $\begin{array}{c}\text { Max Allowed } \\
\text { Weight } \%\end{array}$ \\
\hline $\mathrm{Fe}$ & 98.60 & No Mention \\
$\mathrm{C}$ & 0.20 & 0.26 \\
$\mathrm{Si}$ & 0.29 & 0.50 \\
$\mathrm{Mn}$ & 0.47 & 1.20 \\
$\mathrm{Cr}$ & 0.06 & 0.20 \\
$\mathrm{Ni}$ & 0.10 & 0.40 \\
$\mathrm{Cu}$ & 0.17 & 0.40 \\
$\mathrm{Al}$ & 0.04 & No Mention \\
$\mathrm{P}$ & 0.01 & 0.03 \\
$\mathrm{~S}$ & 0.01 & 0.03 \\
\hline
\end{tabular}

3.1 Preliminarily

Microstructural Observation and Rating of Inclusion Levels

The effect of heating on standard test specimens due to the machining processes of band saw cutting, facing and lathing was investigated. Microstructural evaluation was conducted for the samples obtained from the cylindrical test specimens. It was revealed that the lathe machining process is the appropriate milling method as there was no significant effect on the microstructure of the resultant specimen. The results of microstructural observations were, as expected, showing pearlite regions in a ferrite matrix (Figure 5). There were no observations of laminations and surface or internal cracking (Figure 5). Two samples were cut from the pipe to observe the microstructure from the longitudinal and transverse cross-sections. There were no significant observations of inclusions, however, considering the criticality of inclusions on corrosion and crack propagation processes, an inclusion rating (ASTM E45) was carried out and yielded a nonsignificant result.
3.2 Preliminary Investigations to Distinguish the Effects of Applied Load and $\mathrm{H}_{2} \mathrm{~S}$ Environment

The results from the preliminary investigation to verify the effects of applied load and the presence of $\mathrm{H}_{2} \mathrm{~S}$ environment is shown in Table 2. The predominant formation of a ferrous oxide layer during the exposure of specimens to neutral aqueous environment is referred to as "General corrosion" throughout this paper.

Table 2 - Preliminary Testing- Load at Fracture in Different Environments.

\begin{tabular}{cc}
\hline & Load at \\
Test Type & Fracture \\
& $(\mathrm{N})$
\end{tabular}

(1) Non-Loaded Specimen, Neutral Aqueous Environment 8880

(2) Loaded Specimen, Neutral Aqueous Environment

(3) Loaded Specimen, Sour Environment

SEM images of cross sections of the three types of specimens (mentioned in Table 2) are shown in Figure $6(\mathrm{a}, \mathrm{b}$ and $\mathrm{c})$. Significant difference in the depth to which the corrosion had propagated was observed between the nonloaded and loaded specimens kept in the aqueous solution, the corresponding average depth estimated as $12.2 \mu \mathrm{m}$ and $16.1 \mu \mathrm{m}$ respectively as shown in Figure 6 ( $a$ and $b$ ). The same procedure performed in an aqueous $\mathrm{H}_{2} \mathrm{~S}$ environment (sour) under same loading conditions exhibited more pronounced corrosion propagation with the corresponding average depth of $62.8 \mu \mathrm{m}$ (Figure 6(c)).

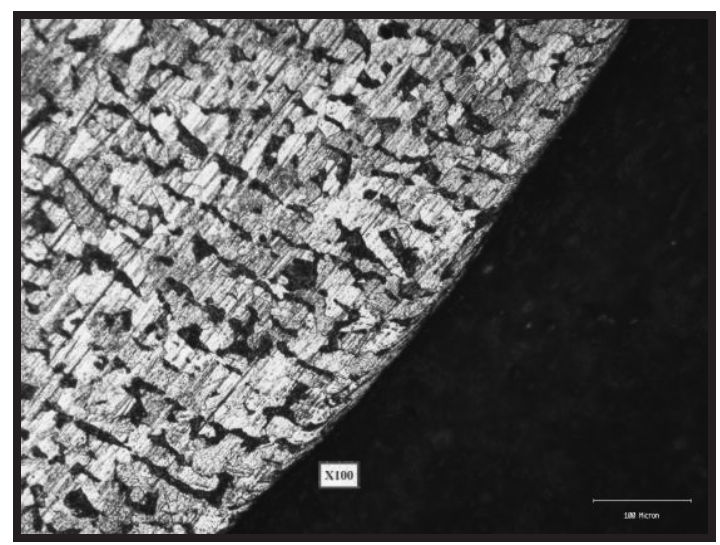

Figure 5 - Surface of the Test Specimen after Machining Process (X100) 

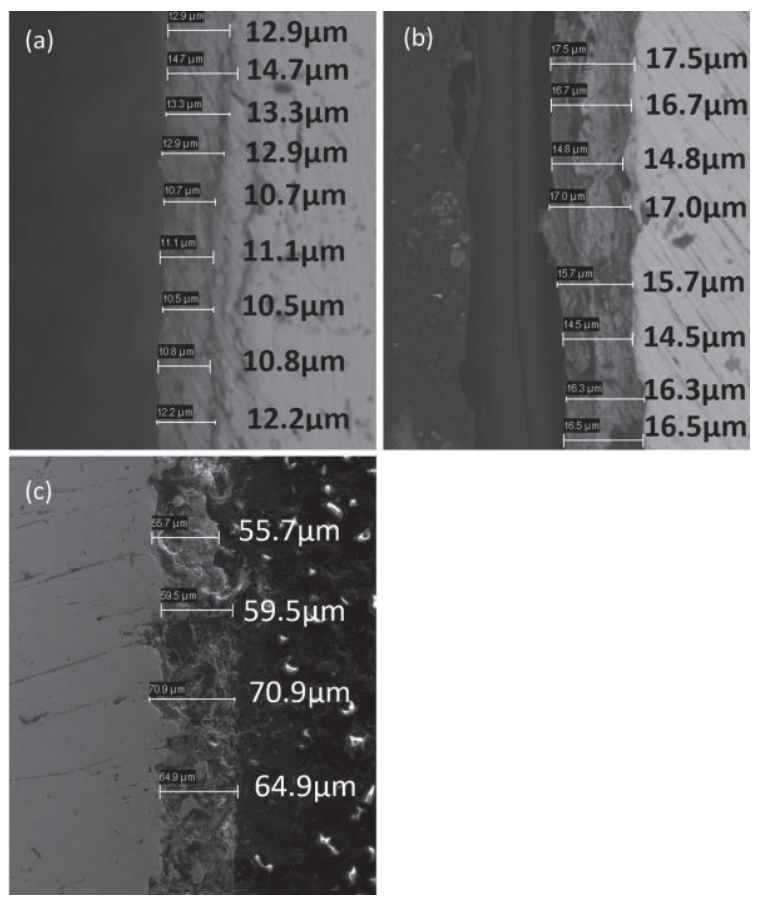

Figure 6 - Depth Observations (after two weeks) - (a) Aqueous EnvironmentUnloaded, at X2000, (b) Aqueous Environment -Loaded $(500 \mathrm{~N})$, at X2000, and (c) $\mathrm{H}_{2} \mathrm{~S}$ Environment- Loaded (500 N), at X350, Dark Region being the Resin of the Mounted Specimen, Measured Distance being the Corrosion Depth and Grey Region being the Unaffected Metal

These results were generally expected since the stress corrosion phenomena and sour environment have been found to accelerate the general corrosion process. However, based on these results obtained for average depth of corrosion and load at fracture, it was decided to vary the exposure time from two weeks onwards.

In this work, lower rate of corrosion under aqueous environment was taken as the reference against the rapid rate of corrosion under $\mathrm{H}_{2} \mathrm{~S}$ environment to present the significant distinction of these two types of corrosion.

\subsection{Variation of Depth of Penetration and Load at Fracture with Increase of Exposure Time}

The load at fracture versus the exposure time period curve is given by Figure 7(a). A lower and consistent decrement of load at fracture is evident in the specimens exposed to the aqueous environment (general corrosion). A linear reduction of load at fracture $-300 \mathrm{~N}$, is recorded from 2 to 12 weeks, which is close to established research data for the initial stages (lower exposure time) of general corrosion. The specimens exposed to the aqueous $\mathrm{H}_{2} \mathrm{~S}$ environment, initially indicate a higher reduction in the load at fracture until around six weeks. However, beyond that limit the load at fracture reduced at a lower rate. The depth of corrosion versus the exposure time curve for the $\mathrm{H}_{2} \mathrm{~S}$ environment given in Figure 7(b) shows a logarithmic increase in the depth compared to the linear growth of the depth in aqueous environment. In the specimens exposed to aqueous $\mathrm{H}_{2} \mathrm{~S}$, the rapid rate of increase in the depth of corrosion during initial few weeks is diminished while a continuous increase in the depth is observed (Figure 7(b)). Initially formed corrosion layer could be acting as a barrier for continuous diffusion of Hydrogen atoms and sulfide ions into the metal. This phenomenon may be a possible reason for lower rate of increase in the depth of corrosion beyond the exposure time of six weeks.

The load at fracture versus the depth of corrosion in an aqueous $\mathrm{H}_{2} \mathrm{~S}$ environment is given in Figure 8. The sigmoidal curve fitted closely around the data points illustrate the change in the load bearing capability of the material. Fracture loads are relatively unaffected up to corrosion depths of around 55 $\mu \mathrm{m}$ after which rapid reduction in the aforesaid capability is evident.

The final specimen exposed for 14 weeks (data point not shown on the plot) was fractured in the exposure period itself, which effectively signaled that there was no continuation of the corrosion curve. These specimens failed without any necking type of deformation and the fracture surfaces lead authors to the conclusion that the metal had indeed succumbed to brittle weakening of the metal. The rapid deterioration of the load bearing ability in between 50-60 $\mu \mathrm{m}$ depths is attributed the development of micro cavities within the corrosion layer and the unaffected metal interface as shown in Figure 9(d).

\subsection{Interpretation of Growth of Corrosion Layer in terms of SEM/EDS Analysis} SEM/EDS elemental mapping was performed to investigate the characteristics of corrosion layer as an initial step of presenting an interpretation for the mechanism of growth of the SSC layer which has not been clearly interpreted yet. 

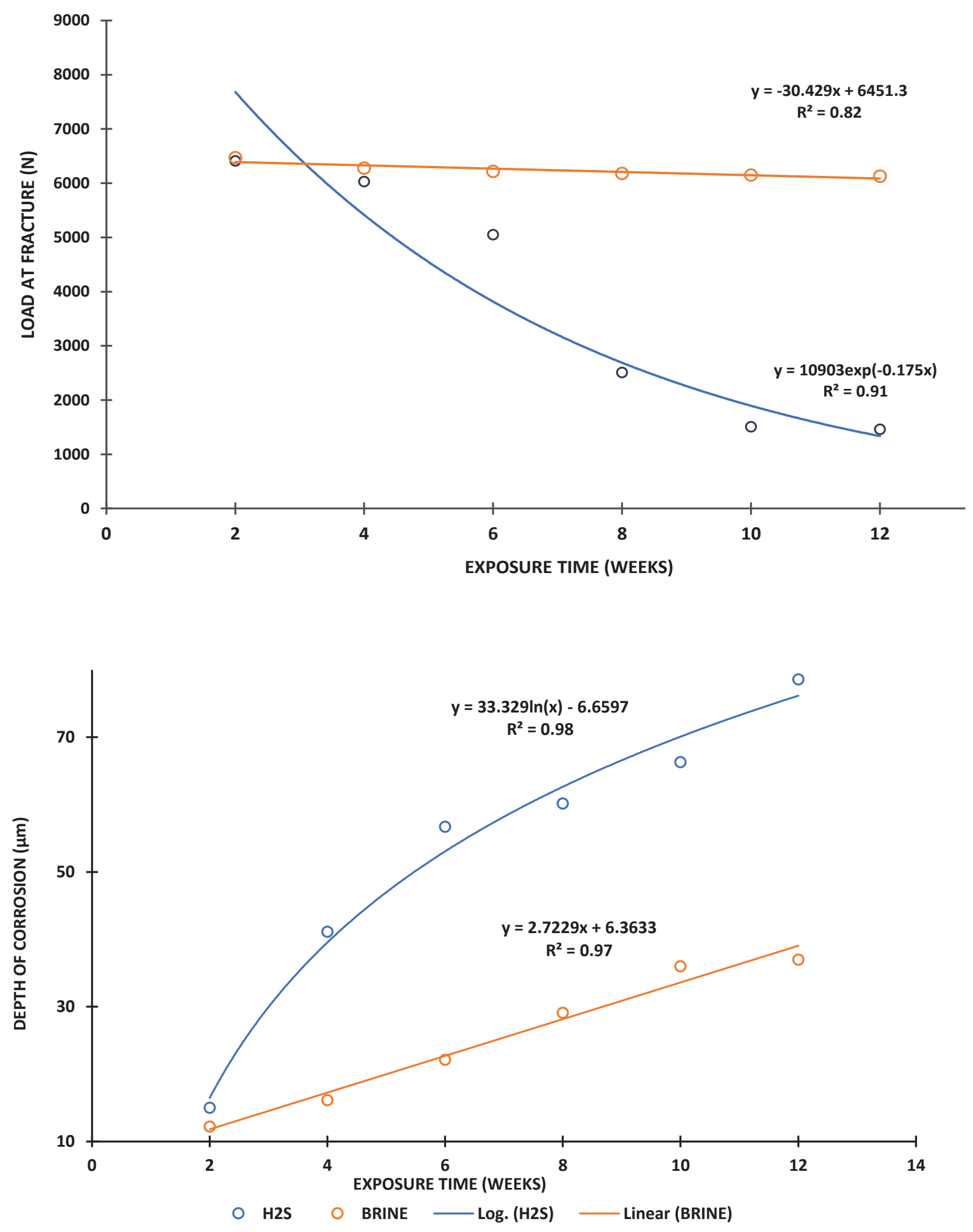

Figure 7 - (a) Load at Fracture vs. Exposure Time (Top) and (b) Depth of Corrosion vs. Exposure Time (Bottom) 
Sulfide layers formed in the corrosion layer during exposure to $\mathrm{H}_{2} \mathrm{~S}$ environment were not continuous and consistent as shown in Figure 10. It was observed that a smooth and continuous interface is developed between the corrosion layer and the unaffected metal during the initial few weeks (Figures 10 (a) and (b)).

However, the interface gradually transformed into an uneven and rough boundary as a result of buildup of micro cracks towards the unaffected metal (Figure 10(c)). Furthermore, it is proposed to carry out an XRD analysis of the corrosion layers to reveal the types of sulfides formed within the corrosion layer.

\subsection{Approach to Develop a Model to Predict the Depth of Corrosion}

The experimental data collected during the 14 weeks was regressed into a sigmoidal function [19] (Equation 02) (Figure 8). The visual observation and goodness of fit $\left(\mathrm{R}^{2}-0.95\right)$ confirm that a very good fit was obtained. The relationship hence identified between the maximum load that can be applied at fracture $(F)$ to the depth to which the corrosion has penetrated $(D)$ is mathematically illustrated using the following function:

$$
F=1475 \cdot 65+\frac{4744 \cdot 52}{\left(1+\mathrm{e}^{\left(\frac{D-58.33}{1.43}\right)}\right)}
$$

The fitted curve closely represents the variation in load bearing capability of the specimen comprising depth of corrosion around $55 \mu \mathrm{m}$ and above. The representation of the constants to physical quantities remains to be studied with further research by varying the parameters such as temperature, applied continuous loading on the specimens, concentration of $\mathrm{H}_{2} \mathrm{~S}_{(\mathrm{aq})}$ etc.

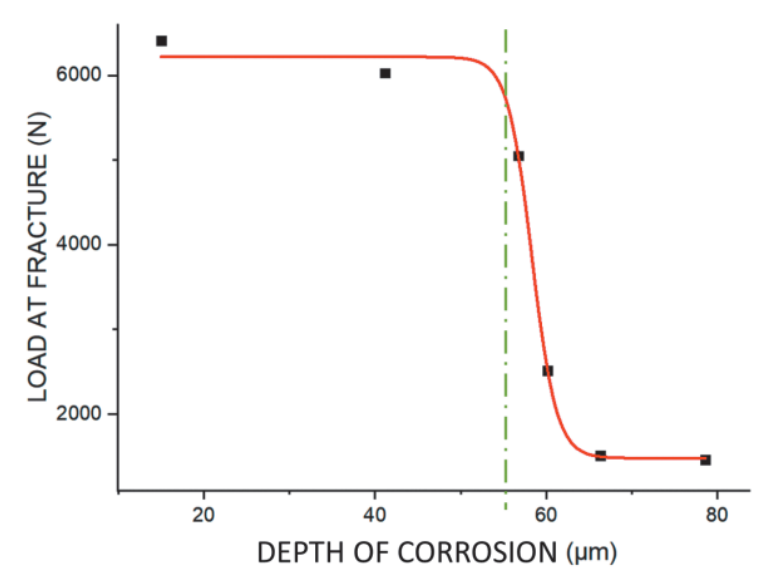

Figure 8 - Variation of Load at Fracture vs. Depth of Corrosion

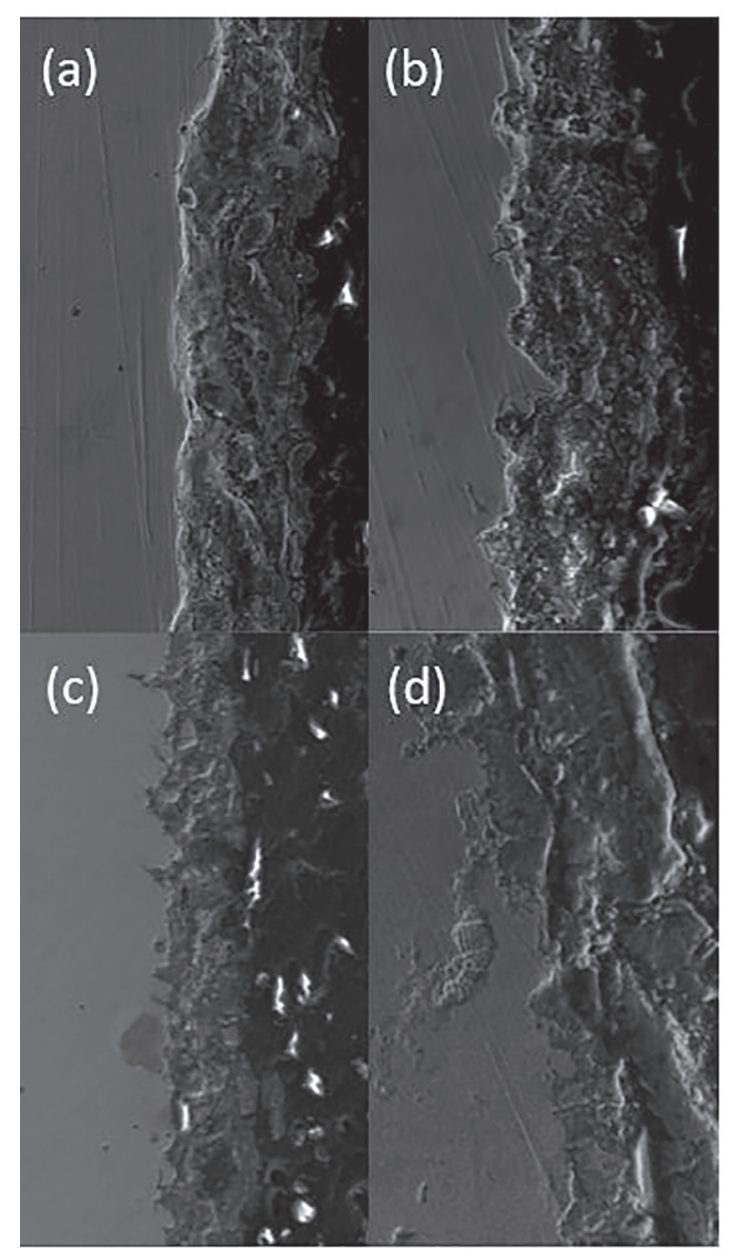

Figure 9 - Development of Microcracks in the Interface of the Corrosion Layer and Unaffected Metal as Corrosion Progresses (X500-1000), (a) 02 Weeks, (b) 06 Weeks, (c) 10 Weeks and (d) 14 Weeks 


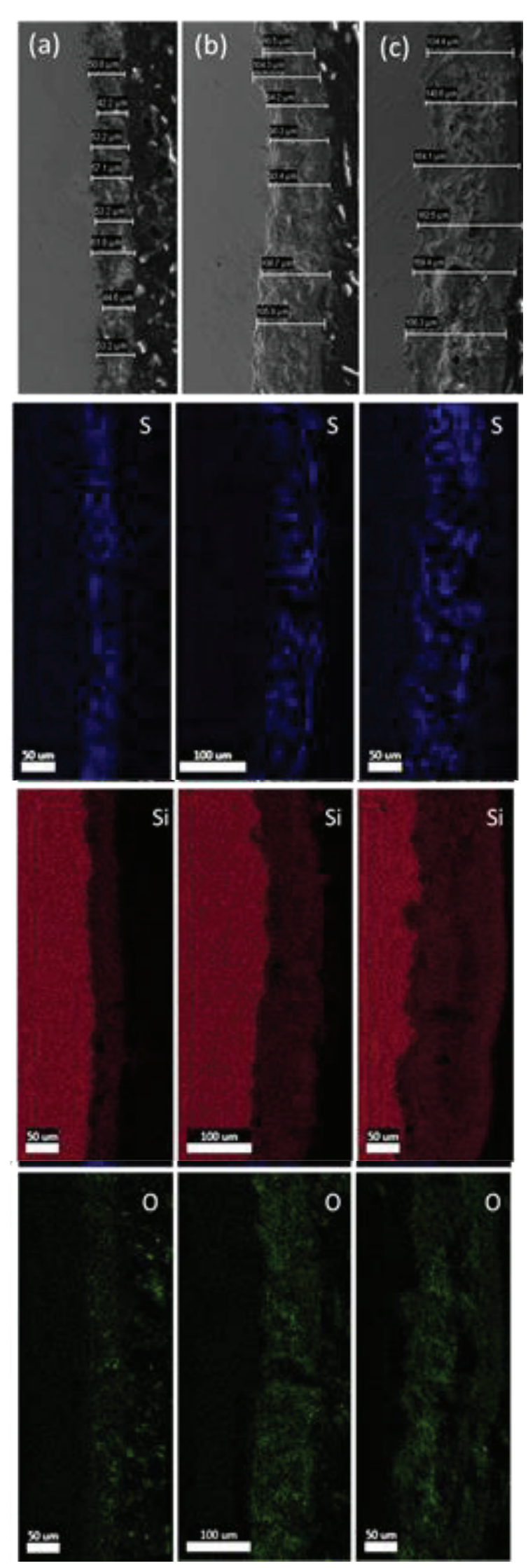

Figure 10 - EDS Elemental Mapping of Corrosion Layers Corresponding to Top Left SEM Images at X350 (a) 02 Weeks, (b) 08 Weeks and (c) 12 Weeks

\section{Conclusions}

- For API 5L Grade B Steel type, a correlation between load at fracture and time period exposed to a constant $\mathrm{H}_{2} \mathrm{~S}$ concentration $\mathrm{pH}$ value of $3.0 \pm 0.5$ under a constant load of of $500 \mathrm{~N}$, was developed as an exponential equation.

- Variation of load at fracture with depth of corrosion closely fits the proposed sigmoidal model within the $55 \mu \mathrm{m}$ to $80 \mu \mathrm{m}$ depth range.

- The progress of developing microcracks towards the unaffected metal has significantly contributed to the drastic reduction in load bearing capability beyond the depth of corrosion around $55 \mu \mathrm{m}$.

- The combined effect of developing microcracks and formation of sulfides within the corrosion layer and base metal has led to the ultimate brittle fracture of specimens.

\section{Acknowledgement}

This research work was funded by SRC (Senate Research Committee) grant offered by the University of Moratuwa. The authors would like to thank all members of the academic and non-academic staff of the Department of Materials Science and Engineering at the University of Moratuwa who assisted this research. Thanks are extended to the Senate Research Council (SRC) grant SRC/LT/2019/07 of University of Moratuwa for the financial assistance. We would also like to express our gratitude to Mr. E.A.S. Edirisinghe (Refinery Manager, Ceylon Petroleum Corporation) and Mr. Srikanth (Senior Mechanical Engineer, Ceylon Petroleum Corporation) for providing steel specimens much needed for this research.

\section{References}

1. Kvarekval, J. and Svenningsen, G., “Effect of High $\mathrm{H}_{2} \mathrm{~S}$ Partial Pressures on Localized Corrosion of Carbon Steel", Proc., Oilfield Chemicals Symposium, Norway, 2014, pp. 7075.

2. Sorrija, Bruno A; Nascimento, \& Marcelino, P., "Fatigue Crack Growth Rate Analysis in an API 5L x70 Steel Pipe," in Rio Pipeline Conference and Exposition, Technical Papers, 2015, vol. 2015-Septe, September 2015. 
3. El-Sherik, A. M., Trends in Oil and Gas Corrosion Research and Technologies Production and Transmission, Woodhead Publishing Series in Energy, 2017, 102 p.

4. Barrera, O., Bombac, D., Chen, Y., Daff, T. D., Galindo-Nava, E., Gong, P. and Sweeney, F., "Understanding and Mitigating Hydrogen Embrittlement of Steels: A Review of Experimental, Modelling and Design progress from Atomistic to Continuum", J. Materials Science, Vol. 53, 2018, pp 6251-6290.

5. TM0177-2016-SG, Laboratory Testing of Metals for Resistance to Sulfide Stress Cracking and Stress Corrosion Cracking in $\mathrm{H}_{2} \mathrm{~S}$ Environments, NACE International, 2016.

6. Munno, T., "Advanced High Strength Steels," Steel Times Int., 2019.

7. Raymond, L., Hydrogen Embrittlement: Prevention and Control, ASTM STP 962, 1988, pp. 403-410.

8. Zapfee, C. A. and Sim, C. E., "Hydrogen Embrittlement, Internal Stress and Defects in Steel, American Institute of Mining and Metallurgical Engineers" (AIME), 1941, pp. 2027.

9. Troiano, A. R., "The Role of Hydrogen and Other Interstitials in the Mechanical Behavior of Metals", J. Metallography, Microstructure, and Analysis, Vol. 5, 2016, pp 557-569.

10. Shi, X., Yan, W., Wang, W. and Zha, L., "HIC and SSC Behavior of High-Strength Pipeline Steels", J. Acta Metall. Sin. (Engl. Lett.), Vol.28, 2015, pp 799-808.

11. Jon, K., Hojin, C., "Formation of Multilayer Iron Sulfide Films During High Temperature $\mathrm{H}_{2} \mathrm{~S}$ Corrosion of Carbon Steel" Proc. NACE International Corrosion Conference Series, California, 2003.

12. Srinivasan, S., "Critical Factors in Predicting $\mathrm{CO}_{2} / \mathrm{H}_{2} \mathrm{~S}$ Corrosion in Multiphase Systems", Proc. NACE International Corrosion Conference Series, California, 1998.

13. Srdjan, N., JiYong, C., Kun, L. L. "A Multiphase Flow and Internal Corrosion Prediction Model for Mild Steel Pipelines" Proc. NACE International Corrosion Conference Series, Texas, 2005.

14. Stephen N. S., Michael J., "Corrosion of Carbon Steel by $\mathrm{H}_{2} \mathrm{~S}$ in $\mathrm{Co}_{2}$ Containing Oilfield Environment" Proc. NACE International Corrosion Conference Series, San Diego, CA, 2006

15. Specification for Line Pipe - API Specification $5 \mathrm{~L}$, 45th Ed., no. December 2012, 2012.
16. ANSI/NACE TM0177, Standard test method laboratory testing of metals for resistance to sulfide stress cracking and stress corrosion cracking in H2S environments, NACE International, no. 21212. 2016.

17. ASTM, "E45-18a Standard Test Methods for Determining the Inclusion Content of Steel," ASTM Int. Conshohocken, PA, www.astm.org, 2018.

18. ANON, “ASME B31.3-2008 Process Piping ASME Code," Chem. Eng., vol. 76, no. 8, 1969, pp. 95-108.

19. Carrillo, M., and González, J. M., "A New Approach to Modelling Sigmoidal Curves," Technol. Forecast. Soc. Change, 2002. 